\title{
Towards a Framework of Literature Review Process in Support of Information Systems Research
}

\author{
Yair Levy, Timothy J. Ellis \\ Nova Southeastern University, \\ Graduate School of Computer and Information Sciences \\ Fort Lauderdale, Florida, USA
}

\author{
levyy@nsu.nova.edu ellist@nsu.nova.edu
}

\begin{abstract}
This paper introduces an initial effort towards developing a framework for writing an effective literature review. The target audience for the framework are novice IS researchers or other researchers who are constantly struggling with the development of an effective literature-based foundation for the proposed research. The proposed framework follows the systematic data processing approach comprised of three major stages: 1) inputs (literature gathering and screening), 2) processing (Blooms Taxonomy), and 3) outputs (writing the review). This paper provides the rationale for developing a solid literature review and addresses the central stage, processing the literature. The paper concludes by providing arguments for the value of an effective literature review as well as implications for future work in this proposed framework.
\end{abstract}

Keywords: Literature review, effective literature review, literature search, literature categorization, literature classification, literature analysis, literature synthesis

\section{Introduction}

A methodological review of past literature is a crucial endeavor for any academic research work (Webster \& Watson, 2002). The need to uncover what is already known in the body of knowledge prior to initiating any research study should not be underestimated (Hart, 1999). Some fields of study have chronically suffered from lack of proper literature review, which in turn has hindered theoretical and conceptual progress (Shaw, 1995a). Webster and Watson (2002) also criticized the Information Systems (IS) field for having very few theories and outlets for quality literature review. Moreover, they noted that the IS field may greatly benefit from an effective methodological literature review in order to strengthen IS as a field of study (Webster \& Watson,

Material published as part of this publication, either on-line or in print, is copyrighted by the Informing Science Institute. Permission to make digital or paper copy of part or all of these works for personal or classroom use is granted without fee provided that the copies are not made or distributed for profit or commercial advantage AND that copies 1) bear this notice in full and 2) give the full citation on the first page. It is permissible to abstract these works so long as credit is given. To copy in all other cases or to republish or to post on a server or to redistribute to lists requires specific permission and payment of a fee. Contact Publisher@InformingScience.org to request redistribution permission.
2002). Therefore, the central aim of this study is to address the issue of developing an effective literature review by proposing a systematic approach that will guide novice researchers on such a daunting task.

This paper is divided into three sections. This first section addresses what a literature review is and why a literature review is crucial for research. The next 
section details a proposed methodology for converting the information from the numerous journal articles, conferences proceedings, books, and other qualified literature sources into a well articulated foundation upon which new research can be built. The final section addresses the value of well processed literature review as groundwork for quality research along with implications for future work.

\section{What is a Literature Review?}

Novice researchers tend to approach the literature review as nothing more than a collection of summaries of papers or an elaborated annotated bibliography of multiple research manuscripts (Webster \& Watson, 2002). A meaningful literature review is much more. Hart (1999) defined the literature review as "the use of ideas in the literature to justify the particular approach to the topic, the selection of methods, and demonstration that this research contributes something new" (p. 1). He also noted that for the literature review, “... quality means appropriate breadth and depth, rigor and consistency, clarity and brevity, and effective analysis and synthesis" (Hart, 1999, p. 1). Shaw (1995a) noted that the process of the review should "... explain how one piece of research builds on another” (p. 326). Webster and Watson (2002) defined an effective literature review as one that “... creates a firm foundation for advancing knowledge. It facilitates theory development, closes areas where a plethora of research exists, and uncovers areas where research is needed" (p. 13). From these definitions it is clear that an effective literature review should include the following characteristics: a) methodologically analyze and synthesize quality literature, b) provide a firm foundation to a research topic, c) provide a firm foundation to the selection of research methodology, and d) demonstrate that the proposed research contributes something new to the overall body of knowledge or advancing the research field's knowledge.

\section{Why Conduct a Literature Review?}

Before examining how to conduct a literature review, one must first understand the place of the review in research (Webster \& Watson, 2002). Thus, three questions must be answered: What is a literature review process? What is research? Why is a literature review needed for any quality research endeavor?

Process is defined as sequential steps of methodological activities (Sethi \& King, 1998). Following the description of what constitutes an effective literature review provided above, combined with the definition of process presented here, this study defines literature review process as: sequential steps of methodological analysis and synthesis of quality literature to provide a firm foundation to a topic, selection of methods, and demonstration that the proposed research contributes something new to the overall body of knowledge. The term body of knowledge (BoK) refers to the cumulative research knowledge achieved by "building on each other's [research] results" (Ivari, Hirschheim, \& Klein, 2004, p. 314).

Research is defined as an endeavor that scholars "intentionally set out to enhance [their] understanding of a phenomenon and expect to communicate what [they] discover to the large scientific community" (Leedy \& Ormrod, 2005, p. 4). Two critical considerations stem from this definition: a) research must enhance the scientific community's current understanding of a phenomenon, or contribute to enhance the "BoK", and b) research must communicate what was discovered in the new study to the scientific community. Knowing the current status of the BoK in the given research field is an essential first step for any research project (Iivari et al., 2004). An effective literature review accomplishes this step by:

1) Helping the researcher understand the existing body of knowledge including where excess of research exists (i.e. what is already known?) and where new research is needed (i.e. what is needed to be known?) 
2) Providing a solid theoretical foundation for the proposed study (related to "what is already known?”)

3) Substantiating the presence of the research problem (related to "what is needed to be known?”)

4) Justifying the proposed study as one that contributes something new to the BoK

5) Framing the valid research methodologies, approach, goals, and research questions for the proposed study

The next three sub-sections will provide some additional elaboration for the need of literature review in the context of any quality IS research.

\section{Build a solid theoretical foundation for your study}

Developing a solid foundation for a research study is enabled by a methodological analyses and syntheses of quality literature (Barnes, 2005; Webster \& Watson, 2002). One of the main reasons for conducting the literature review is to enable researchers to find out what is already known. However, it is important to remember that not everything reported in the literature is of equal rigor (Ngai \& Wat, 2002). When proposing a new study or a new theory, researchers should make use of quality literature to serve as the foundation for their research (Barnes, 2005). Doing so ensures the validity of the study and reliability of the results. Quality literature is one that stimulates additional research studies, which enable validation of the original theory proposed (Barnes, 2005). Straub (1989) noted that "with validated instruments, researchers can measure the same research constructs in the same way, granting improved measurement of independent and dependent variables, and in the long run, helping to relive the confounding that plagues many streams of MIS literature” (p. 148). Moreover, he noted that building a solid theoretical foundation based on quality resources enables researchers to better explain as well as understand problems and solutions that address actual issues with which practitioners are struggling.

Conducting an effective literature review that will yield a solid theoretical foundation should also provide a firm foundation to the selection of the methodology for the study (Ngai \& Wat, 2002). The selection of the methodology should not be interpreted as placing more rigor on one type of research be it qualitative, quantitative, exploratory or confirmatory, rather it should enable the researcher to understand what was previously validated (Straub, 1989). Thus, a solid theoretical foundation should also provide researchers the justifications for a given methodology or enable them to provide justifications for why a given approach is inferior or superior for their study.

\section{How the literature fits into your research?}

An effective and quality literature review is one that is based upon a concept-centric approach rather than chronological or author-centric approach (Webster \& Watson, 2002). Bem (1995) noted that "authors of literature reviews are at risk for producing mind-numbing lists of citations and findings that resemble a phone book - impressive case, lots of numbers, but not much plot" (p. 172). Thus, researchers must continuously ask themselves when reviewing literature and when writing the literature review: 'how is the work presented in the article I read related to my study?' Answering this question will allow researchers to tie the literature into their own study. Moreover, during the review of the literature researchers should utilize sources that substantiate the presence of the problem under investigation (Barnes, 2005). Doing so will enable the researcher to provide a solid argument for the need for their study as well as spot where literature fits into their own proposed study. Moreover, use of literature should provide the grounds for legitimization of the research questions proposed in the study as well as validate the approach proposed by the study. 


\section{Place your study in the context of existing work (body of knowledge)}

Aside from assessing how a given literature article fits into the proposed study, researchers should also address how their proposed study fits in the context of the BoK. As noted above, one of the main definitional components of research is the ability to add to the current BOK. As such, quality research must provide justifications for the potential contributions provided by the proposed study. Such justifications should demonstrate how the proposed research contributes something new to the overall BoK or advances the research field's knowledge. A classic example of this approach is the DeLone and McLean's (1992) paper that noted "the importance of defining the IS dependent variable cannot be overemphasized... in recognition of this importance, this paper explores the research that has been done... and attempts to synthesize this research into a more coherent body of knowledge” (p. 61). The evidence in the contribution of the classical DeLone and McLean's (1992) to the BoK was materialized by the stream of research studies conducted following this paper and was summarized again by them over a decade later (DeLone \& McLean, 2003).

\section{Literature Review: Processing}

Locating applicable peer-reviewed articles is certainly a necessary condition for a literature review (Shaw, 1995b); however, it is not a sufficient condition. The data contained in the sources identified must be processed into information that can serve as a foundation upon which new research can be built (Bem, 1995). Accomplishing this processing entails sophisticated cognitive activity. Although the methodology for evaluating the results of that cognitive activity has been explored rather thoroughly (Boote \& Beile, 2005; Hart, 1999), the ways and means for actually accomplishing the necessary processing is less clearly understood (Wu, 2005). How can the new or novice researcher learn to effectively use the articles he or she locates to build the necessary foundation?

There is certainly no shortage of theories regarding human learning (Gagne, Briggs \& Wagner, 1992; Jonassen, Tessmer, \& Hannum, 1999). “Blooms Taxonomy” (“Taxonomy”) (Bloom, Engelhart, Furst, Hill, \& Krathwohl, 1956) has been shown to both effectively describe the learning process and offer meaningful insight into promoting development within the cognitive domain (Andrews \& Wynekoop, 2004; Manton, Turner, \& English, 2004; Noble, 2004; Zahn, Rajkumar, \& Zahn, 1996). Two concepts are integral to the Taxonomy: cognitive capability is a developmental process that can be tracked through a series of steps, and each step of cognitive development can be identified by a number of specific types of behaviors. In effect, the Taxonomy provides a set of sequential steps, each of which requires gradually more cognitively demanding activities that the researcher should do in developing the skill to transform the raw data of numerous literature sources into an effective literature review. The following sections provide a review of each of the Taxonomy steps, with emphasis on the sequential process that a given step is as the foundation for the followed step.

\section{Know the Material}

The knowledge level is commonly demonstrated by activities such as listing, defining, describing, and identifying. At the very least, the researcher must demonstrate that he or she has read the article and extracted meaningful information from it. Figure 1 presents an example of a citation that points to the literature but does not demonstrate mastery at the knowledge level. Although the citation certainly tells that Nunamaker, among others, had something to say about individual and group marks for in-group activities, the reader really doesn't have any idea what these references said. 
Other research also indicates that individual and group marks should be combined ingroup activities (Buchy \& Quinlan, 2000; Lim et al., 2003; Romano \& Nunamaker, 1998).

\section{Figure 1: Pointing at the literature}

Figure 2 presents this information in a manner that demonstrates knowledge - level mastery of the material. From this example it is clear that the citation provides some germane facts about the Buchy and Quinlan article: it was a report of some research, that the research was qualitative in nature, and that one of the conclusions from that qualitative research was that students participating in tutorial groups reported that the group activity made them more attuned to the learning process.

Buchy and Quinlan (2000) interviewed 36 students participating in tutorial groups. These interviews indicated that the students felt they were becoming more conscious of learning processes of both themselves and their peers.

\section{Figure 2: Knowledge-level mastery}

\section{Comprehend the Material}

Comprehension is demonstrated by activities such as summarizing, differentiating, interpreting, and contrasting. At this level of mastery the researcher demonstrates that not only can he or she repeat what was included in the article but also knows the meaning and significance of the information being reported. Figure 3 illustrates a citation that presents un-interpreted bits of fact.

Han and Kamber (2001) suggest an evolution that moves from data collection and database creation, towards data management, and ultimately, data analysis and understanding.

Figure 3: Pre-comprehension level mastery

Although the citation in Figure 3 certainly indicates the point raised by Han and Kamber, it really does not demonstrate mastery over anything beyond a set of "buzz-words". The amplified citation displayed in Figure 4 demonstrates an understanding of the concepts presented by Han and Kamber.

Han and Kamber (2001) suggest an evolution that moves from data collection and database creation, towards data management, and ultimately, data analysis and understanding. For example, data processing is a base function enabling manipulation and aggregation of data, thus facilitating searching and retrieval.

\section{Figure 4: Comprehension-level mastery}




\section{Apply}

Application is demonstrated by activities such as demonstrating, illustrating, solving, relating, and classifying. In the context of the literature review, application is most directly revealed by the two-step process of: a) identifying the major concepts germane to the study and b) placing the citation in the correct category. Table 1, adapted from Webster and Watson (2002), illustrates the activities necessary to demonstrate mastery at the application level following the concept-centric approach discussed previously.

Table 1: Application-level mastery

\begin{tabular}{|l|c|c|c|c|}
\hline & Concept 1 & Concept 2 & $\ldots$ & Concept $\mathrm{n}$ \\
\hline Article 1 & $\mathrm{X}$ & & & $\mathrm{X}$ \\
\hline Article 2 & & $\mathrm{X}$ & & \\
\hline$\ldots$ & & & $\mathrm{X}$ & $\mathrm{X}$ \\
\hline Article $\mathrm{n}$ & & $\mathrm{X}$ & $\mathrm{X}$ & \\
\hline
\end{tabular}

\section{Analyze}

Analysis is demonstrated by activities such as separating, connecting, comparing, selecting, and explaining. In essence, analysis entails identifying why the information being presented is of importance. Figure 5 illustrates a citation that presents the facts from the literature without the necessary analysis.

Data mining is the analyzing and interpretation of large amounts of information. Through analyzing vast amounts of data it is possible to find patterns, relationships and from these discoveries it is possible to make correlations (Chen \& Liu, 2005).

Figure 5: Knowledge without analysis

Left unanswered by this citation is an insight into why it would be of any interest or value to find patterns and relationships in order to make correlations. Figure 6 presents a modification to the citation that does provide that analysis.

Data mining is a process of discovering new knowledge by using statistical analysis to identify previously unsuspected patterns and clustering in large data sets (Chen \& Liu, 2005).

Figure 6: Analysis-level mastery 


\section{Synthesize}

Synthesis entails activities such as combining, integrating, modifying, rearranging, designing, composing, and generalizing. The essence of synthesis is to assemble the literature being reviewed for a given concept into a whole that exceeds the sum of its parts. Figure 7 illustrates a discussion in which facts are presented as almost a series of isolated "bullet points". Figure 8 presents that same information in a well-synthesized discussion in which the research from a number of sources is very effectively woven together.

The Digital Object Identifier (DOI), is an Internet-based system for global identification and reuse of digital content (Paskin, 2003). It provides a tracking mechanism to identify digital assets (Dalziel, 2004). The DOI is not widely employed across LOR and databases and is not universally adapted by content owners (Nair \& Jeevan, 2004). The DOI does not provide provision for assets to be tagged with copyright information (Genoni, 2004).

\section{Figure 7: Lack of synthesis}

One current DRM initiative, the Digital Object Identifier (DOI), is an Internet-based system for global identification and reuse of digital content, and provides a tracking mechanism to identify digital assets (Paskin, 2003; Dalziel, 2004). However, despite being integrated in learning object technologies, this DOI is not widely employed across LOR and databases, nor is it universally adapted by content owners (Nair \& Jeevan, 2004). Similarly, while most metadata schema enables assets to be tagged with copyright information, this method lacks technological enforcement (Genoni, 2004).

Figure 8: Synthesis-level mastery

\section{Evaluate}

Evaluation connotes activities such as assessing, deciding, recommending, selecting, judging, explaining, discriminating, supporting, and concluding. The essential evaluation in the literature review is to clearly distinguish among opinions, theories, and empirically established facts. Citations such as the one displayed in Figure 9 do not indicate if the material from the literature has been evaluated in any way.

Data mining has applicability to education as well as business (Sanjeev, 2002; Ma et al., 2000; Glance et al., 2005; Abe et al., 2004; Liu et al, 2005).

Figure 9: Non-evaluated citation 
... the applications of data mining fall under the general umbrella of business intelligence. Case studies have reported implementation of data mining applications for:

(1) Enrollment management (to help capture promising students) (Sanjeev, 2002);

(2) Alumni management (to foster donations and pledges) (Ma et al., 2000); (3)

Marketing analysis (to better allocate the marketing funds) (Glance et al., 2005); and

(4) Mail campaign analysis (to judge its effectiveness and design new, better targeted mailings) (Abe et al., 2004). Based upon the similarity to applications within the business community, Liu et al (2005) speculated that data mining could also be used within the educational community for fraud analysis and detection.

\section{Figure 10: Citations demonstrating evaluation}

The material presented in Figure 10, on the other hand, does demonstrate an element of evaluation. The author clearly identifies the type of information being presented - case study reports in the first four citations, opinion in the fifth citation.

\section{Conclusions}

\section{Summary of the Value of Effective Literature Review}

It was suggested that the real value of published research work "is in the dissemination of knowledge for use by others” (Barnes, 2005, p. 110). However, the value or importance of an effective literature review is in ensuring that the researcher demonstrates a full understanding of the BoK related to the phenomenon under study, while at the same time "should be explanatory and creative" (Webster \& Watson, 2002, p. xxi). Moreover, an effective literature review should demonstrate a thorough/systematic examination of the existing BoK by following the sequential processing model discussed above, while demonstrating clear distinctions among opinions, theories, and empirically established facts.

\section{Implications for Future Work - Stages of the Literature Review Process}

This paper presented the groundwork towards an effective literature review process following a systematic framework guided by the traditional data processing model. Following this model, the proposed framework suggests a three stages literature review process to guide novice researchers in the development of a sound and effective literature review. The three stages of the proposed literature review process are: 1) Inputs, 2) Processing, and 3) Outputs. Figure 9 provides an overall view of the process-oriented framework proposed. This paper concentrated in the central stage (literature processing) of the process, while it is the aim of this work to extend this approach towards a robust framework addressing all three stages of the process (1. Literature Review: Inputs; 2. Literature Review: Processing; and 3. Literature Review: Outputs). 


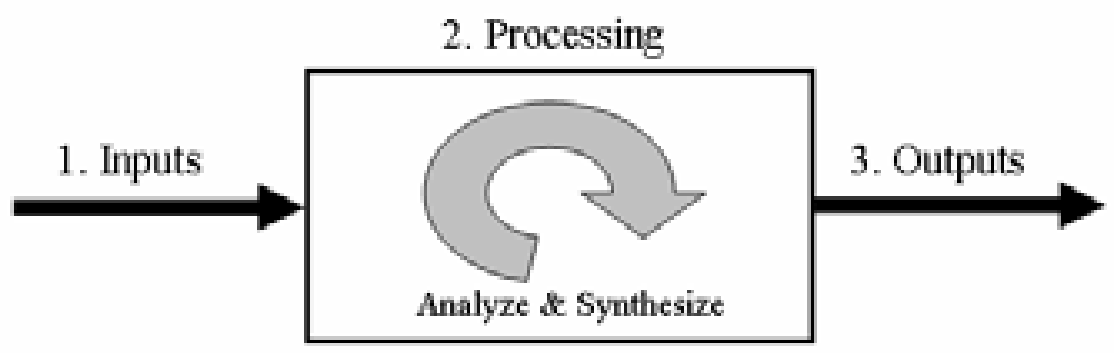

Figure 11: The three stages of effective literature review process

Additional efforts will expand the current work by addressing the inputs as well as the outputs stages. The inputs stage in the process will address issues related to: Finding applicable literature (i.e. literature resources, electronic resources, keywords search, backward searching \& forward literature searching), Qualifying the literature (i.e. validating literature quality - peer reviewed work vs. non-peer reviewed work, various quality levels of peer-reviewed work, etc.), as well as How to read research literature (i.e. cognitive/construct-level, literature streams, theories). The outputs stage in the process will address issues related to: Writing the actual literature review and description of the impact of the BoK as a whole on the proposed study. Moreover, the literature review text itself should be structured to follow a pattern of solid argumentation following the guidelines provided by Toulmin (1958). His argument theory provides guidelines following four sections: 1) claims, 2) evidences, 3) warrants, and 4) backings, as part of the argumentation process. Future work will attempt to elaborate these two stages (inputs and outputs), while providing simple examples for each stage.

\section{References}

Andrews, C. P., \& Wynekoop, J. (2004). A framework for comparing IS core curriculum and IS requirements for accounting majors. Journal of Information Systems Education, 15(4), 437-450.

Barnes, S. J. (2005) Assessing the value of IS journals. Communication of ACM, 48(1), 110-112.

Bem, D. J. (1995). Writing a review article for psychological bulletin. Psychological Bulletin, 118(2), 172177.

Bloom, B. S., Engelhart, M. D., Furst, E. J., Hill, W. H., \& Krathwohl, D. R. (Eds.) (1956) Taxonomy of educational objectives, the classification of educational goals, Handbook I: cognitive domain. New York: Longmans.

Boote, D. N., \& Beile, P. (2005). Scalars before researchers: On the centrality of the dissertation literature review in research preparation. Educational Researcher, 34(6), 3-15.

DeLone, W. H., \& McLean, E. R. (1992). Information system success: The quest for the dependent variable. Information Systems Research, 3(1), 60-95.

DeLone, W. H., \& McLean, E. R. (2003). The DeLone and McLean model of information systems success: A ten-year update. Journal of Management Information Systems, 19(4), 9-30.

Gagne R.M., Briggs L.J., and Wagner W.W.(1992). Principles of Instructional Design. New York: Harcourt Brace Jovanovich College Publishers.

Hart, C. (1999). Doing a literature review. Releasing the social science imagination. London: Sage Publications.

Iivari, J., Hirschheim, R., \& Klein, H. K. (2004). Towards a distinctive body of knowledge for Information Systems experts: coding ISD process knowledge in two IS journals. Information Systems Journal, 14(4), 313-342. 
Jonassen, D. H., Tessmer, M., \& Hannum, W. H. (1999). Task analysis methods for instructional design. London: Lawrence Erlbaum Associates.

Leedy, P. D., \& Ormrod, J. E. (2005). Practical research planning and design (8 ${ }^{\text {th }}$ ed). Upper Saddle River, NJ: Prentice Hall.

Manton, E., Turner, C., \& English, D. (2004). Testing the level of student knowledge. Education, 124(4), 682-687.

Ngai, E. W. T., \& Wat, F. K. T. (2002). A literature review and classification of electronic commerce research. Information \& Management, 39(5), 415-429.

Noble, T. (2004). Integrating the revised Bloom's Taxonomy with multiple intelligences: A planning tool for curriculum differentiation. Teachers College Record, 106(1), 193-211.

Savoy, J. (2005). Bibliographic database access using free-text and controlled vocabulary: An evaluation. Information Processing \& Management, 41(4), 873-890.

Sethi, V., \& King, W. R. (1998) Organizational transformation thought business process reengineering. Upper Saddle River, NJ: Prentice Hall.

Shaw, J. (1995a). A schema approach to the formal literature review in engineering theses. System, 23(3), 325-335.

Shaw, D. (1995b). Bibliographic database searching by graduate students in language and literature: Search strategies, system interfaces, and relevance judgments. Library \& Information Science Research, 17(4), 327-345.

Straub, D. (1989). Validating instruments in MIS research. MIS Quarterly, 13(2), 147-170.

Toulmin, S. (1958). The uses of argument. Cambridge: Cambridge University Press.

Webster, J., \& Watson, R. T. (2002). Analyzing the past to prepare for the future: Writing a literature review. MIS Quarterly, 26(2), 13-23.

Wu, M. M. (2005). Understanding patrons' micro-level information seeking (MLIS) in information retrieval situations. Information Processing \& Management, 41(4), 929-947.

Zahn, S. B., Rajkumar, T. M., \& Zahn, C. J. (1996). Incorporation of student portfolios in the TQM classroom. International Journal of Instructional Media, 23(4), 327-340.

\section{Biographies}

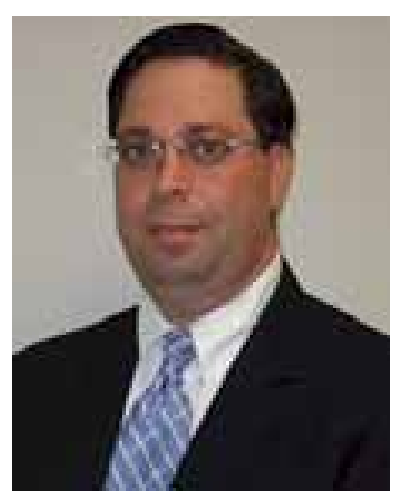

Dr. Yair Levy is an assistant professor of Management Information Systems at the Graduate School of Computer and Information Sciences at Nova Southeastern University. During the mid to late 1990s, he assisted NASA to develop e-learning systems. He earned his Bachelor's degree in Aerospace Engineering from the Technion (Israel Institute of Technology). He received his MBA with MIS concentration and Ph.D. in Management Information Systems from Florida International University. His current research interests include cognitive value of IS, of online learning systems, effectiveness of IS, and cognitive aspects of IS. Dr. Levy is the author of the book "Assessing the Value of eLearning systems”. His research publications appear in the IS journals, conference proceedings, an invited book chapters, and encyclopedias. Additionally, he chaired and co-chaired multiple sessions/tracks in recognized conferences. Moreover, Dr. Levy has been serving as a member of academic review board and a referee research reviewer for numerous national and international scientific journals, conference proceedings, as well as MIS and Information Security textbooks. He is also a frequent speaker at national 
and international meetings on MIS and online learning topics. To find out more about Dr. Levy, please visit his site: http://scis.nova.edu/ levyy/

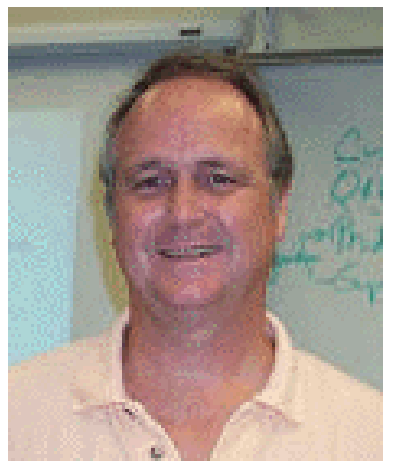

Dr. Timothy Ellis obtained a B.S. degree in History from Bradley University, an M.A. in Rehabilitation Counseling from Southern Illinois University, a C.A.G.S. in Rehabilitation Administration from Northeastern University, and a Ph.D. in Computing Technology in Education from Nova Southeastern University. He joined NSU as Assistant Professor in 1999 and currently teaches computer technology courses at both the Masters and Ph.D. level in the School of Computer and Information Sciences. Prior to joining NSU, he was on the faculty at Fisher College in the Computer Technology department and, prior to that, was a Systems Engineer for Tandy Business Products. His research interests include: multimedia, distance education, and adult learning. He has published in several technical and educational journals including Catalyst, Journal of Instructional Delivery Systems, and Journal of Instructional Multimedia and Hypermedia. His email address is ellist@nova.edu. His main website is located at http://www.scis.nova.edu/ ellist/ 